\title{
RELAÇÕES CIVIS-MILITARES NO BRASIL: INTERPRETAÇÕES SOBRE O "PODER MODERADOR" E AS FORÇAS ARMADAS BRASILEIRAS
}

\begin{abstract}
RESUMO: Fez-se uma revisão bibliográfica sobre o tema das relações civis-militares e a adaptação dessas interpretações no Brasil. Classicamente, os teóricos das relações civis-militares compreendem 4 modelos básicos de relação civis-militares: o modelo aristocrático, o liberal, o comunista e o profissional. Sobre o caso brasileiro, há uma literatura que enfatiza o papel das Forças Armadas no período republicano, sobretudo após os anos 1930, como semelhante ao "Poder Moderador" desempenhado pelo Imperador, consagrado na constituição de 1824. Segundo essa análise, setores da sociedade e os militares - sobretudo o oficialato - entendem que seu papel é agir como força estabilizadora nacional em momentos de crise institucional, política, econômica e social, balizando o jogo democrático e o funcionamento do estado democrático de direito como garante da lei em última instância. Por outro lado, outra corrente critica essa interpretação apontando seus limites. Uma das críticas à interpretação "moderadora" é que ela escamoteia a tradição antidemocrática das Forças Armadas no Brasil, funcionando como instrumento de classe e como poder desestabilizador do sistema político. Espera-se contribuir com o campo ao refletir-se sobre as tradições teóricas do campo no Brasil e, ao mesmo tempo, propondo uma agenda de pesquisas sobre formas recentes de relação civis-militares no país.
\end{abstract}

Palavras-chave: Forças Armadas; Moderador; Relações Civis-Militares.

\section{CIVIL-MILITARY RELATIONS IN BRAZIL: INTERPRETATIONS ON "MODERATING POWER" AND BRAZILIAN ARMED FORCES}

\begin{abstract}
A bibliographic review was made on the subject of civil-military relations and the adaptation of these interpretations in Brazil. Classically, civil-military relations theorists comprise 4 basic models of civil-military relations: the aristocratic, the liberal, the communist and the professional model. On the Brazilian case, there is a literature that emphasizes the role of the Armed Forces in the republican period, especially after the 1930s, as similar to the "Moderating Power" played by the Emperor, enshrined in the 1824 constitution. According to this analysis, sectors of society and the military - especially the official - understands that its role is to act as a national stabilizing force in moments of institutional, political, economic and social crisis, guiding the democratic game and the functioning of the democratic rule of law as guarantor of the law in the last instance. On the other hand, another current criticizes this interpretation, pointing out its limits. One of the criticisms of the "moderating" interpretation is that it conceals the anti-democratic tradition of the Armed Forces in
\end{abstract}

\footnotetext{
${ }^{1}$ Graduado em História (UNIFSJ), Especialista em Política Brasileira (UNIFSJ), Mestre em Sociologia Política (UENF), Doutorando em Sociologia Política (UENF). Professor de História (SEEDUC-RJ). Email: wallace_sm89@hotmail.com
} 
Brazil, functioning as a class instrument and as a destabilizing power of the political system. It is expected to contribute to the academically by reflecting on the theoretical traditions of the field in Brazil and, at the same time, proposing a research agenda on recent forms of civil-military relations in the country.

Keywords: Armed Forces; Moderating Power; Civil-Military Relations

\section{INTRODUÇÃO}

A história do Brasil e o funcionamento e ação das Forças Armadas brasileiras estão intimamente ligadas. Mesmo durante o período do governo de Dom Pedro II, a participação política de militares foi determinante para os rumos políticos do país, como no contexto da Guerra do Paraguai (IZECKSOHN, 1997). Naquele período, a "Questão Militar" era colocada em evidência, e as insatisfações e busca por melhoria nas condições de trabalho, soldos e de reconhecimento social e político se destacavam (SCHULZ, 1994). Entretanto, com a Proclamação da República em novembro de 1889 (CASTRO, 2000) a participação dos militares nos processos políticos do país se tornou ainda mais visível e importante. A partir de então, as Forças Armadas - mais notadamente o Exército Brasileiro - foram fundamentais no desenrolar das questões políticas, econômicas e sociais no país. Durante a nascente república brasileira com os governos dos Marechais Deodoro da Fonseca e Floriano Peixoto (HAHNER, 1975), o primeiro período Vargas, de 1930 a 1945 (FIGUEIREDO, 1979), e a ditadura militar no período de 1964 a 1985, o Brasil foi governado por governos com forte teor autoritário e castrense.

Nos mais diversos temas, os militares estiveram presentes, seja como atores sociais e históricos representando uma classe, grupo ou visão de mundo, seja como instituição que influencia autonomamente o debate público. Durante todo esse processo, as Forças Armadas foram se constituindo em importantes agentes em questões econômicas, educacionais, sociais e culturais. Segundo Castro (2012), os militares foram fundamentais na implantação do ensino de Educação Física nas escolas no Brasil ainda no contexto da primeira República. Isso, segundo o autor, estava ligado ao cuidado com a preparação da população masculina para o serviço militar obrigatório e a passagem pelas Forças Armadas. Além desta, outra questão muito importante é a relação entre as Forças Armadas e o processo de desenvolvimento econômico no Brasil 
na primeira metade do século XX (SAES, 2015). Mesmo no âmbito da cultura e dos valores públicos e nacionais, a participação das Forças Armadas no Brasil é percebida, na medida em que desde antes do nascimento da república, com o movimento republicano paulista na década de 1870, o imaginário político sobre o Brasil foi influenciado pelas visões que dentro das Forças Armadas se desenvolviam, sobretudo o positivismo (CARVALHO, 1990). No contexto da Nova República, os militares estiveram presentes em diversas missões da ONU de pacificação e estabilização, sendo a mais importante a do Haiti (TARDIN, 2015) e em ações de segurança pública.

Em 2018 o ex-capitão do Exército Brasileiro Jair Bolsonaro foi eleito presidente, tendo como vice-presidente o General de Exército Hamilton Mourão. Após vários governos de civis, ele é o pirmeiro presidente brasileiro após a ditadura militar findada em 1985 que tem origem nas Forças Armadas e faz disso um discurso e defesa do referido regime de exceção ${ }^{2}$. Além disso, muito tem se discutido sobre os riscos do governo Jair Bolsonaro converter-se em uma ditadura e representar o fim de um regime democrático incipiente no Brasil ${ }^{3}$

Neste sentido, a compreensão das transformações sociais, econômicas, culturais e sobretudo políticas pelas quais o país passou no século XX exige que se posicione a participação dos militares nos quadros analíticos em questão. Posto de outra forma, é difícil explicar o Brasil sem se explicar como pensaram, se organizaram e agiram as Forças Armadas brasileiras. Longe de representar um juízo de valor, isso é uma constatação dado o inúmero conjunto de momentos e temas - alguns já citados - em que os militares foram importantes.

\section{DOIS CLÁSSICOS DAS RELAÇÕES CIVIS-MILITARES: HUNTINGTON E JANOWITZ}

No esforço de compreensão das relações entre as Forças Armadas e as sociedades, alguns trabalhos se destacaram, seja pela originalidade, seja pelo pioneirismo. Dois merecem destaques e são apresentados aqui: "o Soldado e o Estado"

\footnotetext{
2 Cf: https://istoe.com.br/em-carta-a-onu-governo-bolsonaro-nega-golpe-em-1964/ Acessado em $13 / 08 / 2019$

${ }^{3}$ Cf: https://www1.folha.uol.com.br/mercado/2018/08/bolsonaro-representa-risco-a-democracia-escrevethe-economist.shtml Acessado em 29/08/2019
} 
(HUNTINGTON, 1996[1957]) e "O Soldado Profissional” (JANOWITZ, 1967[1960]). Esses trabalhos, publicados no contexto do pós-II Guerra refletiam a preocupação com a presença das Forças Armadas num momento de ausência de conflitos estatais do porte das duas Grandes Guerras. Nesse sentido, o que fazer com os militares e como lidar com suas demandas vis-à-vis as demandas sociais eram questões que os países desenvolvidos buscavam responder.

O estudo da história militar já era conhecido e difundido, tanto nos EUA e Europa quanto no Brasil, entretanto esse novo cenário político, institucional e internacional, exigia repensar-se os modelos e as interpretações sobre a relação entre o poder militar e o poder civil. Posto de modo mais tradicional, o tema do controle civil entrou na agenda dos estudos políticos e sociológicos sobre as Forças Armadas.

\begin{abstract}
A literatura da área, por influência do trabalho de Samuel Huntington, (1957) privilegia a análise, busca e mensuração do controle civil objetivo sobre os militares, compreendendo-se controle civil como o grau de lealdade que o Estado, através de suas elites políticas, obtém dos militares: o Estado é legal e legitimamente reconhecido como fonte das diretrizes políticas, os militares são autônomos (a partir da direção política) nas atividades inerentes à sua profissão, bem como exclusivos no que se refere à proposição de assuntos estritamente militares, e entende-se profissionalização como o preparo para a guerra e obediência às diretrizes estatais (HUNTINGTON, 1957). (COSTA, 2017, p. 46).
\end{abstract}

Além do referido elemento de controle civil, surge nos estudos sobre Forças Armadas e sociedade no contexto pós-II Guerra um segundo tema importante que o da profissionalização dos militares. O tema será desenvolvidos alguns parágrafos abaixo.

Associado ao tema do controle civil e profissionalização, um segundo desenvolvimento teórico e temático exigiu uma reorganização do campo dos estudos militares: a percepção das Forças Armadas como uma burocracia constituída por grupos e setores diferentes, que longe de se comportarem como um bloco monolítico e acéfalo, possuíam especificidades e elementos constitutivos próprios que tornavam o estudo de seu funcionamento válido.

A profissão militar não é um grupo monolítico de poder. Suas fileiras achamse cindidas por uma profunda divergência relativa à sua doutrina e aos seus pontos de vista sobre relações internacionais, uma cisão que reflete desacordos civis. Pelo contrário, a profissão e a instituição militares, ajustamse antes ao modelo de um grupo de pressão governamental mas possuidor de 
um forte conflito interno de interesses. É um grupo de pressão muito especial, devido aos seus imensos recursos e aos seus graves problemas de segurança nacional. As forças armadas acumularam um considerável poder, e esse poder projeta-se no emaranhado político da sociedade contemporânea. Não podia ser de outra maneira. Contudo, conquanto não relutem absolutamente em fazer pressão visando a maiores orçamentos, as forças armadas exercem sua influência nos assuntos políticos com considerável contenção e constrangimento. $\mathrm{O}$ controle civil dos assuntos militares continua intacto e, como conceito, fundamentalmente aceitável pelas forças armadas; qualquer desequilíbrio nas contribuições militares a questões político-militares internas ou internacionais - é por conseguinte, frequentemente resultado de omissão por parte da liderança política civil. (JANOWITZ, 1967, 8).

A preocupação de Janowitz é problematizar a questão do controle civil, mas ao mesmo tempo, ele propõe pensar as Forças Armadas para além dos preconceitos e estereótipos depreciativos de antes - um grupo monolítico, sem divergências internas. Nesse sentido, transparece no seu texto a questão da atualidade da reflexão sobre o poder das Forças Armadas e da relação entre o poder civil e o poder militar.

\section{A CONTRIBUIÇÃO DE SAMUEL HUNTINGTON}

Samuel Huntington - nascido em 1927 e falecido em 2008 - foi um proeminente cientista político estadunidense responsável por uma grande quantidade de artigos e livros que versavam sobre as questões políticas do seu tempo, tais como a modernização e democratização ao redor do mundo, os conflitos políticos e sobretudo as relações civis-militares. Dentre suas publicações, destaca-se o livro "O Soldado e o Estado", publicado em 1957 e dedicado ao último dos temas acima referidos. Nesse livro, Huntington propõe uma reflexão histórica e teórica sobre a relação entre o poder civil e o poder militar, isto é, entre os agentes civis e militares numa sociedade e estado. $\mathrm{O}$ argumento central de Huntington é o de que "a variável decisiva para que se alcance o assim chamado controle civil objetivo é a profissionalização, ou militarização do militar" (COSTA, 2014, p. 15). A questão apresentada pelo autor da profissionalização, é importante tanto no que se refere à estabilidade democrática quanto ao aumento da segurança. Huntington elabora um complexo arcabouço descritivo e analítico sobre os diferentes tipos de relações civis-militares. Segundo Huntington as variações de controle civil podem ser: a) controle civil subjetivo; b) controle civil por instituição governamental; c) controle civil por classe social; d) controle civil por forma 
constitucional; e, por fim o último dos modelos e) controle civil objetivo (HUNTINGTON, 1997). Cada uma dessas formas de controle possuem um tipo de relação entre as Forças Armadas e a sociedade, também algumas vantagens e desvantagens. De acordo com o autor a forma mais adequada a garantir o controle civil por meio da maximização da profissionalização militar.

No sentido objetivo, controle civil é a maximização do profissionalismo militar. Mais precisamente, é aquela distribuição de poder político entre grupos militares e civis, distribuição que conduz ao aparecimento de atitudes e comportamentos profissionais entre a oficialidade. O controle civil objetivo, opõe-se diretamente a controle civil subjetivo. O controle civil subjetivo atinge seu fim ao tornar civis os militares, fazendo deles espelho do Estado. O controle civil objetivo atinge seu fim ao militarizar os militares, tornando-os instrumentos do Estado. [...] A essência do controle civil objetivo é o reconhecimento do profissionalismo militar autônomo; a essência do controle civil subjetivo é a negação de uma esfera militar independente. (HUNTINGTON, 1997, p. 102).

Huntington empreende uma análise em que dá destaque á preparação para a guerra, isto é à especialização do militar no ofício da guerra. Esse processo de profissionalização tem como consequência um afastamento dos temas políticos contemporâneos, na medida em que se confere à estrutura militar uma autonomia maior para operacionalizar sua função precípua, isto é: a guerra.

\begin{abstract}
A profissionalização compreende o conjunto de atividades, cursos, treinamentos, que visam especializar o militar na condução da guerra, na perfeita administração e operação dos recursos de violência monopolizados pelo Estado. À primeira vista pode parecer uma obviedade assim considerar a profissionalização militar. Entretanto, se for levada em consideração a intimidade entre as Forças Armadas e a própria formação dos Estados modernos, percebe-se claramente como o elemento central para a imposição de uma dada ordem coordenada por uma autoridade central é a aplicação da força física: muito do que se compreende como a luta dos reis para impor sua autoridade passa pelo processo de legitimação do exercício da força física por uma única instituição. As Forças Armadas, bem se vê, detém poder suficiente para encurralar a autoridade central. A profissionalização pretende resolver esse problema: como fazer com que uma instituição criada para instrumentalizar a força não se volte contra o próprio Estado. A resposta de Huntington é a profissionalização. (COSTA, 2014, p. 16).
\end{abstract}

$\mathrm{Na}$ medida em que se profissionaliza, o militar estaria mais apto a garantir a segurança e outros valores sociais importantes numa dada sociedade, pelo fato de que 
essa autonomia da estrutura militar estaria subordinada ao poder civil configurado pela lei.

Em que pese o fato desse trabalho ser um clássico com mais de 60 anos de publicação, em que pese também o fato do modelo analítico proposto por Huntington possuir vários problemas de efetivação - como por exemplo a necessidade de um certo grau de estabilidade democrática para e efetividade prática da teoria - e um certo grau mesmo de reducionismo das experiências de relação civil-militares ao redor do mundo, importa refletir sobre como Huntington conceitua a melhor relação entre o poder civil e os militares a partir da retirada dos militares do cenário político público e sua afirmação profissional para a guerra.

\section{A CONTRIBUIÇÃO DE MORRIS JANOWITZ}

Morris Janowitz foi um sociólogo estadunidense que nasceu em 1909 e faleceu em 1988. Tendo publicado e pesquisado sobre Sociologia Histórica, questões urbanas e, sobretudo, relações civis-militares. Sobre esse tema, o grande livro da Janowitz é "O Soldado Profissional" de 1960 - três após a publicação do livro de Huntington. Assim como ele, em sua análise Janowitz.

\footnotetext{
destaca que a questão do profissional militar, tratado como um especialista, é recente na história, um processo iniciado na Segunda Guerra e aprofundado durante a Guerra Fria. Isso porque, como já destacado, o desenvolvimento das tecnologias bélicas a partir da corrida armamentista aliado ao processo político que envolveu a Guerra Fria, impulsionou a necessidade de uma especificidade maior do profissional militar. (GARCIA, 2018, p. 7-8).
}

Um ponto importante da contribuição de Morris Janowitz ao estudo das relações civis-militares é o fato de sua perspectiva se aproximar muito dos estudos sociológicos da "Sociologia das Instituições", isto é, Janowitz elabora uma análise que dá conta não apenas dos fatores políticos e da relação entre os militares e o setor civil, mas busca demonstrar a originalidade das questões militares frente às questões civis, ou seja, há toda uma dimensão interna às Forças Armadas enquanto instituição que é importante ser levada em consideração na análise sobre o papel dos militares na sociedade. 


\begin{abstract}
A profissão militar é mais do que uma ocupação: é todo um estilo de vida. $\mathrm{O}$ oficial faz parte de uma comunidade cujas exigências sobre sua existência diária transcendem seus deveres oficiais. [...] A missão fatal da guerra tem exigido que o oficial esteja preparado para abandonar sua rotina e seus compromissos pessoais de um momento para outro. Isto é óbvio e prosaico. Contudo, um pouco menos explícito é o fato de que qualquer profissão que se preocupe continuamente com a ameaça de perigo requer uma forte senso de solidariedade para que possa funcionar com eficiência. A regulamentação minuciosa do estilo de vida militar tem o fim de realçar a coesão grupal, a lealdade profissional e manter o espírito marcial. Em boa medida, a doutrinação militar tem sido eficiente devido à comunidade relativamente fechada em que os militares tem vivido. Por sua vez, o estilo de vida da comunidade militar contribui para a auto-confiança e auto-consciência da elite militar. (JANOWITZ, 1967, p. 175).
\end{abstract}

A atenção do autor gira em torno, também das questões organizacionais dos militares, o que dá um caráter novo e complexifica as relações com os setores civis, sobretudo o Estado. A profissionalização cria, constrói subjetividades que, por sua vez, também impactam nas questões públicas e políticas dentro e fora das Forças Armadas. Compreender o papel ativo das idiossincrasias da caserna é fundamental na delimitação dos tipos e formas de relações civis-militares de um dado país. O comportamento dos indivíduos é transformado a partir de um conjunto de atividades que acabam por construir um conjunto de lealdades e de solidariedade. Ao se refletir sobre as relações civis-militares, mais do que atentar para as questões políticas sobre as Forças Armadas, é importante se considerar também o caráter organizacional que influencia e orienta o comportamento da instituição.

\footnotetext{
Morris Janowitz (1960) reforça que, além das características que garantem a especialidade do oficial militar, as Forças Armadas só conseguem existir e coexistir com a sociedade civil, se reservarem os preceitos da hierarquia, disciplina e obediência. Esses três elementos garantiriam, segundo o autor, a institucionalidade das Forças Armadas, pois faria com que a correlação de forças fosse equilibrada, uma vez que os civis não possuem acesso às armas. A noção de "equilíbrio de poder" é usada pelos dois autores, em sentidos semelhantes. Ambos demonstram que os militares constituem um poder independente à sociedade (CARCIA, 2018, p. 8).
}

Esse processo de construção de solidariedade se desenvolve sobretudo a partir das atividades baseadas na Hierarquia, na Disciplina e Obediência. Para o bem funcionamento e bom desenvolvimento da tropa visando o exercício da guerra, ou nos termos weberianos do "monopólio legítimo do exercício da força física", a profissionalização será tão mais efetivada quanto maior foi o grau de hierarquização, 
obediência e disciplinarização dos militares. Essa pode ser vista como uma das grandes contribuições de Janowitz para o estudo das relações civis-militares, qual seja a de apresentar um quadro analítico complementar - em certo sentido - à Huntington em que os elementos sociológicos da estrutura organizacional militar surgem e ganham força.

No Brasil, um trabalho importante sobre as relações civis-militares e que caminhou metodológica e conceitualmente em sentido semelhante, ainda que não idêntico, foi o de Edmundo Campos Coelho "Em Busca de Identidade: o Exército e a política na sociedade brasileira (2000[1976]). Partindo das discussões sobre o funcionamento das Forças Armadas como instituições, isto é, também a partir de uma perspectiva organizacional, Coelho (2000)

\begin{abstract}
O enfoque utilizado é o organizacional. Apesar da variedade de interesses e orientações teóricas e metodológicas cobertas pela teoria organizacional, sua característica distintiva consiste em tomar a organização, e não o sistema inclusivo ou partes dele, como a unidade de análise. Está ênfase na organização não exclui a questão das relações com a organização, por um lado, e seu contexto ambiental, por outro. Pelo contrário, por que formas uma organização se relacional com o seu ambiente externo e como se influenciam mutuamente são questões que constituem o núcleo da análise. (COELHO, 2000, p. 42).
\end{abstract}

A perspectiva que Coelho (2000) utiliza enfatiza o papel da solidariedade, da disciplina e dos valores castrenses na relação estabelecida, sobretudo pós-1930 entre os setores militares e civis no Brasil. Essa análise considera os elementos históricos e organizacional das Forças Armadas. Sendo assim, segundo a análise do professor Frederico Costa “A perspectiva de Coelho (2000) apresenta as Forças Armadas como uma organização que enxerga a si mesma como detentora do poder de excepcionalidade constitucional e instituição adequada para disciplinar a caótica sociedade brasileira". (2013, p. 47).

Segundo Coelho (2000) os militares no Brasil queixam-se de um fenômeno histórico desagradável: "a dupla orfandade"

\footnotetext{
Primeiro a orfandade funcional [...] Creem firmemente que a sociedade e sua elite política não lhes tem qualquer apreço, considerando-se perfeitamente dispensáveis no que tem como sua destinação precípua, a função clássica de defesa nacional. [...] a isso soma-se o sentimento de orfandade institucional a convicção de que não há quem os ouça, se interesse pelas questões que lhes são caras, quem advogue a favor de seus pleitos. (COELHO, 2000, p. 19).
} 
Dado que os militares carecem de apoio institucional e de uma estrutura funcional clara, sobretudo no contexto republicano, segundo essa leitura, os militares buscariam um papel institucional e funcional que legitimasse sua existência enquanto organização. Isso, por si só, não justifica o conjunto de ações e participações em movimentos políticos e sociais no Brasil ao longo do século XX, mas nos ajuda a compreender de que modo se estrutura uma reflexão que permite a participação dos militares na política brasileira.

\section{AS RELAÇÕES CIVIS-MILITARES NO BRASIL: O PADRÃO MODERADOR DE ALFRED STEPAN}

Alfred Stepan, nascido em 1936 e falecido em 2017, foi um cientista político e professor universitário de grande importância no estudos dos movimentos e processos políticos no século XX, sobretudo sobre as questões ligadas ao binômio democraciaautoritarismo. Grande parte de seus escritos focam na análise de regimes autocráticos ou não democráticos e na análise sobre burocracias e poder estatal. Destacam-se em seus escritos também, uma atenção especial ao fenômeno das relações civis-militares. Nesse campo, Stepan escreveu o livro "Os Militares na Política: as mudanças de padrões na vida política brasileira" (1975[1971]).

Stepan inova ao apresentar os padrões de relação civil-militar existentes modelos que representam as melhores condições e controle civil sobre os militares mas propor uma adaptação e um novo padrão para as relações civis-militares brasileiras. $\mathrm{Na}$ verdade, poder-se-ia afirmar que Stepan inova ao pensar a aplicabilidade dos modelos eurocêntricos e estadunidenses à realidade latino-americana. Se trata não apenas de uma projeção de modelos elaborados sobre outras sociedades para os países na América do Sul e Central, mas também de um certo grau de adaptação dessas teorias à história e a trajetória política e social dos países e questão.

Segundo ele, haveria, pelo menos quatro modelos básicos: o modelo aristocrático, o modelo liberal, o modelo comunista e o modelo profissional (STEPAN, 1975, 46-47). Cada um desses modelos possui uma historicidade e um conjunto de características próprio. No modelo aristocrático, há uma congruência grande entre a 
elite aristocrática e a elite militar. Nesse sentido, o oficialato militar é formado por aristocratas que conservam seu prestígio e riqueza e apoiam o governo aristocrata. No modelo liberal, o papel dos militares é muito reduzido, sobretudo a momentos de guerra, e rapidamente desmobilizados na medida em que se teria, teoricamente, uma sociedade civil forte e instituições fortes que possam enfrentar as ameaças à segurança. Os exemplos citados por Stepan são a Suíça e os EUA no século XIX. O terceiro modelo seria o comunista, o ideal liberal do militar apolítico é abandonado em razão de uma vinculação forte entre os militares e a sociedade. Nesse sentido,

consegue-se essa integração "através da politização do soldado profissional, que não mais é tratado como um expert, mas age também como membro do partido comunista e através deste participa das decisões políticas, não como soldado, mas como cidadão politicamente ativo" (STEPAN, 1975, p. 48).

O último modelo apresentado por Stepan é o profissional. A concepção apresentada por Stepan de profissionalismo é muito próxima à de Huntington, na medida em que enfatiza que

Consegue-se o controle civil "não porque os grupos militares partilham valores sociais e ideologias políticas da sociedade, mas porque são indiferentes a tais valores e a tais ideologias. Os líderes militares obedecem ao governo não porque concordem com suas políticas mas simplesmente porque é sua obrigação obedecer. (STEPAN, 1975, p. 48).

Retomando Huntington, há uma posição de que o aumento da distância entre os militares e a política e o debate político é saudável para o exercício do controle civil.

Existe controle civil subjetivo numa grande variedade de formas, mas controle civil objetivo só existe numa única forma. A antítese de controle civil objetivo é a participação do militar na política: o controle civil diminui à medida que os militares se envolvem progressivamente em política institucional, classista e constitucional. Por outro lado, controle civil subjetivo pressupõe esse envolvimento. (HUNTINGTON, 1997, p. 102).

Após apresentar esses quatro modelos supracitados, Stepan propõe um novo modelo para se pensar a relação civil-militar no Brasil: o padrão moderador. Partindo de uma releitura do Poder Moderador durante o período do Império Brasileiro, Stepan interpreta, em países sul-americanos, uma situação tal onde as instituições políticas são 
fracas e o poder das elites e grupos políticos (dentro e fora do governo) são fortes, haveria uma tendência a cooptação dos militares para a ação em movimentos políticos e sociais. "Nesse tipo de sociedade, os militares também são politizados e todos os grupos tentam cooptá-los para aumentar sua força política" (STEPAN, 1975, p. 49).

Haveria uma certa correção na teoria das relações civis-militares na medida em que aquilo que é visto como o desviante ou o equívoco em outras interpretações, aqui, no modelo moderador funciona como sendo um pressuposto teórico afinado à "dependência da trajetória" (path dependence).

\begin{abstract}
Em tal modelo de relações entre civis e militares, estes são chamados repetidas vezes para agir como moderadores da atividade política, mas lhes é negado sistematicamente o direito de tentar dirigir quaisquer mudança dentro do sistema político. Longe de se constituírem nos "construtores da nação" ou nos "reformadores", como são encarados em alguns países, no modelo moderador os militares tem uma tarefa que consiste essencialmente na atividade conservadora de manutenção do sistema. O papel dos militares, de modo geral, se restringe à deposição do chefe do executivo, e à transferência do poder político para grupos alternativos civis. A aceitação desse papel pelos militares está condicionada à sua aceitação de legitimidade e de praticabilidade das formas políticas parlamentares, bem como à constatação, por parte destes militares, de que possuem, em comparação com os civis, uma capacidade relativamente reduzida de governar. (STEPAN, 1975, p. 50).
\end{abstract}

Sobretudo entre os anos de 1945 a 1964, mas podendo ser aplicado a outros contextos pregressos, Stepan busca explicar o padrão de interferência e participação dos militares nos processos políticos do Brasil no contexto. O cenário muda em 1964, pois com o Golpe de 01 de abril, os militares abandonam - a princípio - o padrão de intervenções momentâneas e assumes as rédeas do processo político, tutelando o sistema político brasileiro e a própria dinâmica civil-militar.

Nesse sistema, os militares funcionariam como uma espécie de guarda pretoriana. Segundo Costa “A perspectiva moderadora, enfatizando o caráter pretoriano da sociedade brasileira, acentua a intensa politização das relações sociais no Brasil versus a baixa institucionalidade verificada, incapaz de lidar com as tensões sociais e políticas de um país em efervescência (no mínimo até 1964)” (2013, p. 47).

A importância do conceito de padrão moderador aponta para a possibilidade de constituição de uma força política relevante - como o são as Forças Armadas - que 
possuiria um direcionamento doutrinário de certa ingerência em temas políticos e sociais e de quem, em certa medida, depende a estabilidade política do país.

\title{
A CRITICA DE JOÃo QUARTIM DE MOARES: O MITO DO PODER MODERADOR
}

João Quartim de Moraes é professor da Universidade Estadual de Campinas. Graduado em Ciências Sociais e Jurídicas e também em Filosofia, doutorou-se em filosofia, publicando, estudante, lecionando e pesquisando sobre diversos temas caros às Ciências Sociais, sobretudo os temas ligados ao estudo dos marxismos - diferentes concepções - e também da política brasileira. Dentre as diversas contribuições dados por esse autor, destaca-se o diálogo com a literatura sobre as relações civis-militares no Brasil e o papel dos militares na política brasileira. Publicado em 1985, "Alfred Stepan e o mito do poder moderador" é um texto duro, crítico e muito profundo em que Moraes discute a aplicabilidade e viabilidade teórica, metodológica e empírica do conceito de poder moderador para interpretar a participação dos militares na política no Brasil e o modelo de relação civil-militar - se é que há um modelo. Dado o espaço reduzido, aqui apenas serão apontados alguns pontos da crítica feita por Moraes.

A crítica construída por Quartim de Moraes se assenta na confusão epistemológica de Stepan, ao mesmo tempo de indeterminabilidade histórica.

\begin{abstract}
O exame pormenorizado das demais proposições que compõe o "modelo moderador" nos levaria a constatar a mesma ambiguidade, a mesma indeterminabilidade histórica. Embora algumas dessas proposições seja à primeira vista menos imprecisa (a proposição $\mathrm{n}^{\circ} 5$, por exemplo é verificável: "existe uma crença firme entre as elites civis e militares de que, embora seja legítima para estes a intervenção no processo político e no exercício temporário do poder, é ilegítimo que assumam a direção do sistema político por longos períodos de tempo"), padecem todas da mesma ambiguidade epistemológica. (MORAES, 2001, p. 62).
\end{abstract}

No que se refere à historiografia política e a participação militar na Primeira República, Moraes (2001) endossa a posição de Carvalho (2019b) de que as Forças Armadas brasileiras funcionaram na Primeira República como um poder desestabilizador, isto é, longe de representar um elemento de estabilidade do regime 
político, os militares e sua participação política agiram como elementos de agitação do sistema político. Segundo Moraes, Carvalho (2019b).

apoiando-se em documentação historiograficamente mais rica e rigorosamente controla, caracteriza as intervenções militares durante a I República como um poder desestabilizador. Essa interpretação, frontalmente oposta à de Stepan, já que "moderar", "compor" significam estabilizar, confirma nossa hipótese sobre as condições institucionais da hegemonia da "aliança do café [...] (MORAES, 2001, p.71).

Além disso, Moraes elabora uma crítica ao próprio uso indevido da analogia do Poder Moderador no período do Império. Há uma dissonância entre o exercício do poder moderador por um indivíduo - Dom Pedro II - e a aplicabilidade a uma organização complexa e bastante heterogênea como os militares, mormente o Exército.

\begin{abstract}
Quanto ao poder real, neutro ou moderador, introduzido no século XIX por Benjamin Constant, o fato de ter sido invocado, com finalidades apologéticodoutrinárias, para justificar o intervencionismo militar em nosso país, a partir de duvidosa analogia entre o poder do Imperador e o dos militares na República, constitui uma dupla mistificação, do ponto de vista do ideário liberal-democrático no qual pretendem se situar seus apologistas e doutrinários. Em seu sentido próprio, não passa de um elenco juridicamente desconexo de atribuições discricionárias outorgadas a um Imperador que, sem chegar a ser um monarca absoluto (Pedro I bem que o tentou, mas sem sucesso), tampouco pode ser considerado como um monarca constitucional no sentido inglês do termo. Em seu sentido figurado (o "poder moderador dos militares") a mistificação é ainda mais tosca sobretudo quando, como ocorre no conhecido The Military in Politics, de Alfred Stepen, vem revestida de uma roupagem científica. O "poder mantenedor" das Forças Armadas não passa um enxerto autocrático no corpo constitucional liberal. [...]A Constituição liberal de 1946 restabeleceu, com a separação dos poderes, o caráter estritamente militar do "poder mantenedor", retornando, portanto, ao tradicional hibridismo institucional de nossa história republicana: um Estado liberal militarmente tutelado. (MORAES, 1989, p. 71-72).
\end{abstract}

A perspectiva de Moraes indica claramente uma visão sobre o Poder Moderador como um subterfúgio teórico, tanto antes como agora, de legitimação do status quo de participação e tutela militar do jogo político democrático.

Nesse sentido, a crítica de Moraes se aproxima do comentário de José Murilo de Carvalho (2019a) sobre a participação dos militares no contexto atual do Brasil. 
vez, dificultam a consolidação das práticas democráticas. Estamos presos nessa armadilha e não conseguiremos escapar dela se não construirmos uma economia forte, uma democracia includente e uma República efetiva. Não o conseguimos em duzentos anos de vida independente, e o tempo joga contra nós. (CARVALHO, 2019a, p. 25).

A análise de Carvalho (2019a) sobre o caráter cíclico de instabilidade política e de intervencionismo militar na política nacional ganhou um novo cenário com a entrada de militares em diversos postos da administração pública a partir da posse de Jair Bolsonaro. Esse processo não se inicia com Bolsonaro, mas ganha contornos de política de governo clara a entrada e o uso de militares em postos estratégicos nas mais variadas funções.

Ainda é cedo para elaborar conclusões definitivas, o processo está ocorrendo enquanto estas palavras são escritas, mas não se pode prescindir da análise e consideração sobre o papel dos militares na política, tanto do passado quanto da atualidade.

\section{À GUISA DE UMA CONCLUSÃO}

Buscou-se nesse pequeno texto demonstrar a importância de uma tradição literária sociológica, política e histórica no Brasil sobre a participação dos militares na política. Muito longe de esgotar o tema, apontou-se para algumas teorias e interpretações clássicas e importantes, algumas de suas incongruências, mormente do uso do conceito de Poder Moderador. A seleção de trabalhos não foi completa, e nem poderia: o campo, apesar de relativamente pequeno, já conta com diversos trabalhos e uma certa consolidação que dificulta explorar na totalidade todos os trabalhos.

O ponto fundamental, para encerrar o trabalho, é demonstrar que a presença dos militares na política no Brasil, sobretudo num momento em que o país é presidido por um militar, exige criatividade conceitual e analítica e dedicação nas leituras e estudo dos clássicos para a melhor compreensão dos desafios e questões que a conjuntura apresenta.

Os trabalhos cotejados aqui, longe de encerrar o tema, podem permitir reflexões, atualizações, críticas e correções teóricas, metodológicas e empíricas - sobretudo à luz dos novos achados historiográficos e metodológicos - que podem ser fundamentais na 
compreensão dos temas políticos e na construção de uma democracia mais forte, inclusiva e numa República e um espírito republicano no país, de fato.

\section{REFERÊNCIAS BIBLIOGRÁFICAS}

CARVALHO, José Murilo. Uma República tutelada. In: CARVALHO, José Murilo. Forças Armadas e política no Brasil. São Paulo: Todavia, 1ª edição, 2019a.

CARVALHO, José Murilo. As Forças Armadas na Primeira República: o poder desestabilizador. In: CARVALHO, José Murilo. Forças Armadas e política no Brasil. São Paulo: Todavia, $1^{a}$ edição, $2019 b$.

CARVALHO, José Murilo. Forças Armadas e política, 1930-45. In: CARVALHO, José Murilo. Forças Armadas e política no Brasil. São Paulo: Todavia, 1ª edição, 2019.

CASTRO, Celso. A Proclamação da República. Rio de Janeiro: Jorge Zahar, 2000.

CASTRO, Celso. A Invenção do Exército Brasileiro: Rio de Janeiro: Jorge Zahar, 2002.

COELHO, Edmundo Campos. Em Busca de Identidade: o Exército e a política na sociedade brasileira. Rio de Janeiro: Ed. Record, 2000.

COSTA, Frederico Carlos de Sá. As Forças Armadas, a Fundação e Manutenção da Ordem: uma relação estéril. Perspectivas, São Paulo, v. 44, p. 41-59, jul./dez. 2013.

COSTA, Frederico Carlos de Sá. A relação civil-militar e os estudos estratégicos. Revista Teoria e Sociedade. Número 22 Volume: 1 - janeiro-junho de 2014.

COSTA, Frederico Carlos de Sá. Subsídios para o estudo da Teoria Política das relações entre civis e militares. Revista HOPLOS, Vol. 1, Número 1. Rio de Janeiro. 2017.

FERREIRA, Oliveiros. Vida e morte do partido fardado. São Paulo: Editora SENAC São Paulo, 2000. (série Livre Pensar).

FIGUEIREDO, Eurico de Lima (coord.). Os militares e a Revolução de 30. Rio de Janeiro, Paz e Terra, 1979.

GARCIA, Felipe Ramos. A Formação Militar Profissional: Uma leitura A partir das obras de Morris Janowitz e Samuel Huntington. Trabalho apresentado no 10 Encontro Nacional Da Associação Brasileira dos Estudos de Defesa. Setembro de 2018. Disponível em: <https://www.enabed2018.abedef.org/resources/anais/8/1535669209_ARQUIVO_Enab ed2018-Artigo.pdf $>$. 
GÓES MONTEIRO, General Pedro Aurélio de. A Revolução de 1930 e a finalidade política do Exército. Adersen Editores, s/d.

HAHNER, June. As Relações entre Civis e Militares no Brasil: 1889-1898. São Paulo: Pioneira, 1975.

HAYES, Robert A. Nação Armada: a Mística Militar Brasileira. Rio de Janeiro: Bibliex, 1991.

HUNTINGTON, Samuel. O soldado e o Estado: teoria e política das relações entre civis e militares. Rio de Janeiro: Bibliex, 1996.

IZECKSOHN, Vitor. O Cerne da Discórdia: a Guerra do Paraguai e o núcleo profissional do Exército Brasileiro. Rio de Janeiro: Bibliex, 1997.

JANOWITZ, Morris. O Soldado Profissional: um estudo social e político. Rio de Janeiro: Edições GRD, 1967.

MORAES, João Quartim de. O poder Constituinte e a força. Revista Estudos Avançados. Vol.3 No7, São Paulo Sep./Dec. 1989.

MORAES, João Quartim de. Alfred Stepan e o mito do poder moderador. In: MORAES, João Quartim de. Liberalismo e Ditadura no Cone Sul. Campinas: Editora da UNICAMP, 2001.

SAES, Guillaume Azevedo Marques de. O desenvolvimento brasileiro segundo a visão militar, 1880-1945. Curitiba: Editora Prismas, 2015.

SCHULZ, John. O Exército na Política: Origens da Intervenção Militar, 1850-1894. São Paulo: EDUSP, 1994.

STEPAN, Alfred. Os militares na Política. Rio de Janeiro: Editora Artenova, 1975.

TARDIN, Elaine Borges. O Exército brasileiro no Haiti: a reconstrução de uma imagem manchada pela ditadura militar. Curitiba, Appris, 2015. 